\title{
DIFFERENT MODES OF ACTION OF CLONIDINE ON ISOLATED CANINE VEINS
}

\author{
Hiromichi TSURU, Tadao SHOJI* and Tatsuro SHIGEI* \\ Department of Pharmacology, Hiroshima University School of Medicine, \\ Kasumi. Minami-ku. Hiroshima 734, Japar, \\ * Department of Pharmacology. Nagoya University School of Medicine. \\ Showa-ku, Nagova 466. Japan
}

Accepted July 7, 1983

It seems now well established that postjunctional $\alpha$-adrenoceptors in the circulatory system consist of $\alpha_{1}$ - and $\alpha_{2}$-subtypes (see review 1). Clonidine, a selective $\alpha_{2}$-adrenoceptor agonist, has been employed as a useful tool to differentiate between $\alpha_{1}$ and $\alpha_{2}$-adrenoceptors $(1-5)$, although it is well-known to have many faces (6). However, there is little information regarding the mechanism of action of clonidine on isolated veins. In the present study, we show two different modes of action of clonidine on isolated canine veins using longitudinal strips of the portal vein and helical strips of the saphenous vein. These preparations exhibit fairly good contractions in response to clonidine (4).

The portal vein and the saphenous vein were isolated from male mongrel dogs ( $8-12$ $\mathrm{kg}$, body weight) anesthetized with pentobarbital sodium (35 $\mathrm{mg} / \mathrm{kg}$. i.v.). Longitudinal and helical strips of approx. $1.5 \mathrm{~mm}$ in width and $8 \mathrm{~mm}$ in length were prepared from the portal vein and the saphenous vein. respectively, under a dissecting microscope. The strip was suspended in an organ bath which contained $50 \mathrm{ml}$ of modified Krebsbicarbonate solution aerated with $95 \% \mathrm{O}_{2}+5 \%$ $\mathrm{CO}_{2}$ and maintained at $37^{\circ} \mathrm{C}$. The composition of the solution in $\mathrm{mM}$ was: $\mathrm{NaCl}$, 119; $\mathrm{KCl}, 4.7: \mathrm{CaCl}_{2}, 2.5 ; \mathrm{KH}_{2} \mathrm{PO}_{<}, 1.18$; $\mathrm{MgSO}_{4}, 1.17$ : $\mathrm{NaHCO}_{3}, 24.9$ and glucose, 11.1; and the solution contained the ancillary drugs, $3 \times 10^{-6} \mathrm{M}$ propranolol, $3 \times 10^{-5} \mathrm{M}$ cocaine and $3 \times 10^{-5} \mathrm{M}$ corticosterone in order to match the experimental conditions used the previous study (4). A passive load of $1.0 \mathrm{~g}$ was applied to each strip. Isometric contractions were recorded by means of force-displacement transducers (Nihon Kohden, model SB-1T) on ink-writing recorders (Hitachi, model 056). During an equilibration period of $2 \mathrm{hr}$, submaximal contractions were elicited twice by $10^{-5} \mathrm{M}$ norepinephrine, and the bathing media were renewed approx. every $20 \mathrm{~min}$ before the experiments on drug effects. When their effects on the response to clonidine were tested, tissues were exposed to either $10^{-7} \mathrm{M}$ prazosin or $10^{-7} \mathrm{M}$ yohimbine 1 hr prior to the experiment. The concentration-response curve for clonidine was obtained in a cumulative manner from each strip in the absence (as a control) or in the presence of either prazosin or yohimbine. The moderate concentration of antagonists used was chosen on the basis of their $\mathrm{pA}_{2}$ values against norepinephrine $(2,4,5,7)$.

Drugs used were clonidine hydrochloride (Boehringer-ingelheim), cocaine hydrochloride (Takeda), corticosterone (Sigma), prazosin hydrochloride (Pfizer), dl-propranolol hydrochloride (Inderal, 1.C.I.) and yohimbine hydrochloride (Sigma), Statistical analysis was made using Student's $t$-test and differences between means were considered significant when $P$ values were less than 0.05 . Mean concentration-response curves for 
clonidine in the absence and in the presence of $\alpha$-adrenoceptor antagonists are shown in Fig. 1 A for the portal vein and B for the saphenous vein, respectively. Table 1 summarizes the effects of $10^{-7} \mathrm{M}$ prazosin and $10^{-7} \mathrm{M}$ yohimbine on the concentrationresponse curves. The maximum responses to clonidine were not altered by the antagonists in both veins (Table 1). The portal vein was less sensitive to clonidine than the saphenous vein $(P<0.025)$. The alterations of the clonidine concentration-response curve by two distinct $\alpha$-adrenoceptor antagonists clearly reveal the different modes of action of clonidine on the portal vein and the saphenous vein.

In the portal vein, the selective $\alpha_{1}$ adrenoceptor antagonist prazosin shifted the curve in parallel to the right remarkably $(P<0.0001)$, whereas the selective $\alpha_{2}-$ adrenoceptor antagonist yohimbine shifted it a small, but significant amount $(P<0.025)$. This feature of antagonism indicates that clonidine elicited contractions of the longitudinal strip of portal vein via $\alpha_{1}$-adrenoceptors. This notion is consistent with that of Docherty and Starke who used xylazine instead of clonidine as a selective $\alpha_{2}$ -
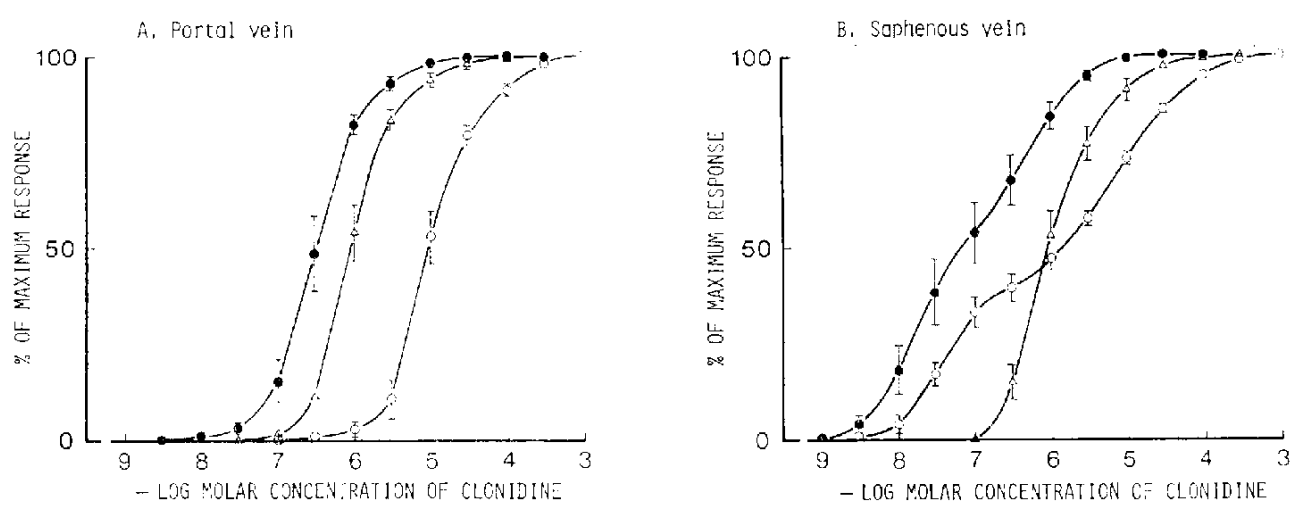

Fig. 1. Mean concentration-response curves for clonidino in the absence (control, 9 ) and in the prosence of $10^{-7} \mathrm{M}$ prazosin (O) and $10^{-7} \mathrm{M}$ vohimbine ( $\Delta$ ). A. The longitudinal strips of the portal vein $(n=5)$. B. The helical strips of the saphenous vein $(n=6)$. Vertical bars represent standard orrors.

Table 1. Summary of live effects of $10^{-7} \mathrm{M}$ prazosin and $10^{-7} \mathrm{M}$ yohimbine on the clonidine concentration-response curve

\begin{tabular}{|c|c|c|c|c|c|c|}
\hline \multirow{2}{*}{ Vein } & \multicolumn{2}{|c|}{ Control } & \multicolumn{2}{|c|}{ Prazosin } & \multicolumn{2}{|c|}{ Yohimbine } \\
\hline & $\operatorname{EC} 50(M)^{1}$ & $T_{\text {:n:l } x}(g)^{2}$ & D.R..$^{3}$ & $T_{\max }(g)^{2}$ & D.R. ${ }^{3}$ & $T_{\max }(\mathrm{g})^{2}$ \\
\hline Portal & $2.98 \times 10^{-7}$ & & 30.6 & & 3.1 & \\
\hline$(n=5)$ & $\left(1.90-4.52 \times 10^{-7}\right)$ & $3.61 \pm 0.54$ & $(24.1-38.9)$ & $3.74 \pm 0.35$ & $(2.2-4.3)$ & $3.60 \pm 0.50$ \\
\hline Saphenous & $6.89 \times 10^{-8}$ & & 15.0 & & 14.4 & \\
\hline$(n=6)$ & $\left(2.46-19.3 \times 10^{-8}\right)$ & $2.45=0.27$ & $(4.9-45.8)$ & $2.26 \pm 0.28$ & $(7.2-28.8)$ & $2.13 \pm 0.28$ \\
\hline
\end{tabular}

1 EC50, clonidine concentration in the bath producing a contraction which is $50 \%$ of the maximum.

2 Triax, mean maximum response to clonidine $\pm S . E$.

3 D.R. EC50 of clonidine in the presence of an antagonist divided by the control clonidine EC50. $95 \%$ confidence intervals are shown in parentheses. 
adrenoceptor agonist with the rabbit portal vein (8). It is of interest to note that the circular strip of portal vein hardly responded to clonidine, but responded well to norepinephrine (mixed type of agonist) and to phenylephrine ( $\alpha_{1}$-selective agonist) (4). Such differences might be due to a smaller or larger number of spare receptors (7).

in contrast, the saphenous vein exhibited the characteristic antagonism. EC50 values of clonidine were similarly increased by prazosin $(P<0.005)$ and yohimbine $(P<$ 0.0005 ) (Table 1). Even the control concentration-response curve for clonidine looked biphasic: this was more exaggerated by prazosin (Fig. 1B): prazosin remarkably shifted the higher part of the curve for clonidine more than the lower part. Inflection points of the curves in the absence and in the presence of prazosin ranged from 30 to $60 \%$ of the maximum response to clonidine. Therefore, EC50 values varied widely in these cases (Table 1). On the other hand. yohimbine markedly inhibited effects of lower concentrations of clonidine, and thus. made the slope of the curve steeper. These features of antagonism indicate that lower concentrations of clonidine clicited contractions via $\alpha_{2}$-adrenoceptors and at higher concentrations, via $\alpha_{1}$-adrenoceptors, being consistent with other results $(5,7,8)$. De Mey and Vanhoutte (2) and we (4) found that prazosin did not cause a parallel shift to the right of the concentration-response curve to norepinephrine, decreasing the slope of the curve, in the carine saphenous vein. This phenomenon might also be due to the characteristic population of $\alpha$-adrenoceptor subtypes in the vein.

Docherty and Starke have shown theoretical concentration-response curves for an agonist acting on two receptors, although they did not find their experimental data suitable for them (8). The present results from the saphenous vein seem to fit their theoretical curves, and this preparation might be a useful tool for the analysis of the interaction between $\alpha_{1}$ and $\alpha_{2}$-adrenoceptors.

Acknowledgement: We wish to thank Nippon Boehringer-Ingelheim and Taito Pfizer for the generous gifts of clonidine and prazosin, respectively.

\section{References}

1) Langer, S.Z. and Shepperson, N.B.: Recen: developments in vascular smooth muscle pharmacology: The post-synaptic $\alpha_{2}$ adrenoceptor. TIPS 3, 440-444 (1982)

2) De Mey, J. and Vanhoutte, P.M.: Uneven distribution of postjunctional alpha - and $^{-}$ alphas-like adrenoceptors in canine arterial and venous muscle. Circ. Res. 48, 875-884 (1981)

3) Ruffolo, R.R., Jr., Yaden, E.L. and Waddell, J.E.: Receptor interactions of imidazolines. $V$. Clonidine differentiates postsynaptic alpha adrencrgic receptor subtypes in tissues from the rat. J. Pharmacol. Exp. Ther. 213, 557-561 (1980)

4) Shoii, T., Tsuru, H. and Shigei, T.: Regional differences of postjunctional $\alpha_{1}$ - and $\alpha_{2}$ adrenergic responses in canine venous system. Japan. J. Pharmacol. 32, Supp. $188 \mathrm{P}$ (1982)

5) Sullivan, A.T. and Drew, G.M.: Pharmacological characterisation of pre- and postsynaptic $\alpha$ adrenoceptors in dog saphenous vein. Naunyn Schmiedebergs Arch. Pharmacol. 314, 249$258(1980)$

6) Kobinger, W.: Clonidine, a drug with many faces? TIPS 2, 194-196 (1981)

7) Starke, K. and Docherty, J.R.: Types and functions of peripheral a-adrenocepiors. J. Cardiovasc. Pharmacol. 4, S3-S7 (1982)

8) Docherty, J.R. and Starke, K.: Postsynaptic $\alpha$ adrenoceptor subtypes in rabbit blood vessels and rat anococcygeus muscle studied in vitro. J. Cardiovasc. Pharmacol. 3, 854-866 (1981) 